ARTICLE

https://doi.org/10.1057/s41599-018-0206-5

\title{
Addressing socioeconomic inequality in access to university education: an analysis of synergies and tensions in Scottish policy
}

\author{
Edward M. Sosu ${ }^{1}$, Lauren N. Smith¹, Ninetta Santoro ${ }^{2} \&$ Stephanie McKendry $^{1}$
}

\begin{abstract}
International research suggests that access to higher education has a significant impact on individuals' life chances and their standard of living, yet university student populations often do not reflect the broader societies from which they are drawn. In Scotland, where students from wealthy backgrounds are four times more likely than students from lower income backgrounds to go to university, reducing the higher education access gap has become a key government policy priority. This study investigates synergies and tensions in contemporary Scottish policies aimed at widening access to higher education. The data for analysis consisted of 35 key Scottish policy documents on widening access to university published from 2011 to 2016. Drawing on the work of key social justice theorists (Rawls, Young and Sen) as our analytic framework, we identified important synergies which include policy interventions targeting the multiple causes of the access gap. We also identified tensions in the form of widening access policy ambitions being tempered by meritocratic admissions processes that do not favour the most disadvantaged, as well as financial support systems that may lead to higher debt burden for students from low income households. We make recommendations for financial support and high-quality guidance for students from low income families and call for regulations requiring universities to demonstrate the impact of their access policies and strategies. Attending to these synergies and tensions will contribute to increased equity and access to university for students from disadvantaged socioeconomic backgrounds.
\end{abstract}

\footnotetext{
${ }^{1}$ University of Strathclyde, Glasgow, Scotland. ${ }^{2}$ Swinburne University of Technology, Melbourne, Australia. Correspondence and requests for materials should be addressed to E.M.S. (email: edward.sosu@strath.ac.uk)
} 


\section{Introduction}

nternational research suggests that access to higher education has a significant impact on individuals' life chances and their standard of living (Crawford et al., 2016). Other evidence also suggests that university student populations do not reflect the broader societies from which they are drawn. In particular, students from the most economically disadvantaged backgrounds across a range of low, medium and high-income societies, remain persistently under-represented (Jerrim et al., 2015; OECD, 2015; Ilie and Rose, 2016). Factors associated with economic disadvantage account for such a gap in access to university (Avery, 2010; Iannelli et al., 2015; Sosu et al., 2016). Specifically, there is evidence that by the end of upper secondary school, pupils from low income households are less likely than their more affluent peers to have achieved the levels of education required to qualify for university entrance (Chowdry et al., 2013; Sosu and Ellis, 2014; Pitman et al., 2015).

The disparity in access to higher education based on socioeconomic status has gained the attention of international organisations and governments in many countries (McCowan, 2007; UNESCO, 2015; Reed et al., 2015; Msigwa, 2016). In Scotland, where students from wealthy backgrounds are four times more likely than students from lower income backgrounds to go to university (Scottish Government, 2016), reducing the higher education access gap has become a key government policy priority (Scottish Government, 2011; Universities Scotland, 2013). For instance, the First Minister of Scotland announced in November 2014 that:

[A] child born today in one of our most deprived communities will, by the time he or she leaves school, have the same chance to go to university as a child born in one of our least deprived communities. That means we would expect at least $20 \%$ of university entrants to come from the most deprived $20 \%$ of the population. (Scottish Government, 2014a, para. 105-106)

There is also a policy commitment by Government that 'higher education in Scotland must always be based on the ability to learn and never on the ability to pay' (Scottish Government, 2011, p. 9). This commitment is exemplified by free tuition for all Scottish domiciled students attending a Scottish university, in comparison to other parts of the UK where students must pay tuition fees. Additionally, in 2015, the Scottish Government established a commission to address questions around how to widen access and subsequently appointed a Commissioner for Fair Access ([COWA], 2015).

Despite an absence of tuition fees for higher education and the introduction of several policies and initiatives aimed at addressing the issue of inequitable access to higher education in Scotland, there has been limited impact on the numbers of young people from economically disadvantaged backgrounds gaining university entrance (COWA, 2015; Hunter Blackburn et al., 2016; Sosu et al., 2016). An analysis by the Commission for Widening Access in 2015 noted that the percentage of students from Scotland's most deprived areas attending university only rose by 3 percentage points from about 11 to $14 \%$ over a ten-year period. International studies have suggested that tensions underpinning university access policies can significantly influence the effectiveness of such policies (McCowan, 2007; Wilson-Strydom, 2015; Msigwa, 2016). For example, in Tanzania, Msigwa (2016) found that uncertainty surrounding the purposes of a financial assistance policy designed to widen access to university limited its effectiveness. Specifically, absence of clarity in defining who is from a 'poor family', and a clause which indicated that support should be given to students enroling in priority programmes, created ambiguity that enabled students from wealthy families to benefit from the scheme. In
Brazil, McCowan (2007) identified several tensions in widening access policies such as a loan policy that required students to have a guarantor with income twice that of the total student loan. This policy was ineffective in widening access to university due to the inability of students from low income households to provide guarantors.

Drawing on the above evidence, we speculate that in part, the limited success of widening access policies in Scotland may be due to tensions in these policies. While there is a commitment from the Scottish Government that access to university should be available to all, irrespective of socioeconomic background, such a commitment is underpinned by principles of meritocracy and availability of limited places, a point to which we will return.

The study on which this article reports uses a theoretical framework incorporating key concepts of social justice from the work of Rawls $(1971,1999,2001)$, Young $(1990,2006)$ and Sen $(1979,1999,2000)$ to investigate synergies and tensions in contemporary policies aimed at widening access for students from low socioeconomic backgrounds in Scotland. In what follows, we discuss our theoretical framework, present our methodology and findings, and discuss the synergies and tensions inherent in the widening access policies that we examined. We conclude by suggesting ways in which the inherent tensions can be addressed.

\section{Theories of social justice and access to university}

John Rawls' theory of distributive justice asserts that social justice is achieved when all individuals have equal access to social, cultural, political and economic resources. His concept of 'justice as fairness' is based on two fundamental principles: a 'liberty principle' whereby each person has an equal right to basic liberties; and a 'difference principle', whereby inequalities in the distribution of goods are viewed as socially just, only when they are of the greatest benefit to the least advantaged (Rawls, 1999). The redistribution of resources to achieve more equitable outcomes is a central tenet of Rawls' notion of social justice. The least advantaged are identified according to whether they possess the primary goods required to improve their life prospects (Rawls, 1999).

In the context of social democracies, resource distribution is often underpinned by principles of meritocracy which are widely accepted as a fair means of distributing finite resources (Liu, 2011). Individuals are given opportunities and/or resources if they can demonstrate having met defined criteria. For example, in the distribution of university places, educational qualifications and/or previous experience is considered a sign of merit and worthiness. While the distribution of resources on the basis of merit is widely accepted as a fair way of identifying which individuals deserve a place at university (Liu, 2011), it is potentially problematic because it ignores the social structures and conditions that either inhibit or promote particular individuals achieving these measures of merit. From a Rawlsian perspective, such a model of distribution is not necessarily socially just because achievement is not simply a result of individual effort or ability. The social conditions into which a person is born and subsequently exposed to, shapes what is possible and what is achievable. Rawls (1971) argues that a person can have as little control over the social conditions that enable the development of merit as they do over other factors, such as their race. Furthermore, many manifestations of meritocracy do not account for the various forms of disadvantage that affect an individual's opportunities to gain qualifications (Young, 2006; Liu, 2011).

Young $(1990,2006)$ argues that the use of merit to allocate scarce and desirable resources such as jobs and qualifications is not socially just. Specifically, in relation to access to education, 


\section{Table 1 Summary table of widening access interventions and relevant key policy documents}

Widening access interventions

Legislating for widening access

- Funding body (SFC) and universities required by law to widen access

- Power for funding body (SFC) to impose conditions on universities to

comply with widening access ambitions

- Requirement for SFC to review widening access targets and take action to correct imbalances

Outcome agreements

- Universities required to specify plans for widening access

- University funding tied to fulfilment of agreed widening access targets

amongst other objectives

- Potential for SFC to impose financial penalties on universities for noncompliance
Selected policy documents

$\otimes$ Putting learners at the centre: Delivering our ambitions for post-16 education $\triangleright$ Post-16 Education (Scotland) Bill

$\otimes$ Post-16 Education (Scotland) Act

$\diamond$ Legislation explanatory notes

$\triangle$ Putting learners at the centre: Delivering our ambitions for post-16 education $\triangleright$ Post-16 Education (Scotland) Bill and explanatory notes

$\triangleright$ Learning for All: Measures of Success. Ninth update
- Extra funded places for access students

- Articulation places for learners moving from college to university $\triangleright$ University sector outcome agreements

$\triangleright$ Learning for All: Fifth update report on measures of success

$\otimes$ Overview of SFC strategic investments in access

$\triangleright$ Articulation and Progression: SFC Access and Inclusion Committee documents

$\otimes$ Learning for All: Measures of Success. Ninth update

Outreach schemes

- General university application support and guidance, attainment and aspiration raising programmes

- Specific support for access to high demand disciplines $\triangleright$ Universities Scotland's 'Access All Areas' publication

$\triangleright$ SFC's Annual reports and review recommendation implementation update document

$\triangleright$ Putting learners at the centre: Delivering our ambitions for post-16 education $\otimes$ Overview of SFC strategic investments in access

$\otimes$ SFC's Schools for Higher Education Programme (SHEP) review
Financial support

- Free tuition

- Grants/ bursaries

- Loans to cover living cost $\triangle$ Putting learners at the centre: Delivering our ambitions for post-16 education $\nabla$ Student Awards Agency Scotland Funding Guide

$\nabla$ Scottish Government's 'Helping you meet the costs of learning and training: Your guide to funding' publication she contends that proxies of merit such as standardised testing are not 'normatively and culturally neutral assessments of individual performance' (Young, 1990, p. 206). As such, they are not adequate measures of whether an individual deserves certain resources. She asserts that the notion of merit serves to further entrench ideologies and authorities sustaining inequality, discrimination, oppression and marginalisation.

Young acknowledges the importance of resource distribution but claims that distribution should not be limited to primary goods, but should extend to social and cultural goods to achieve equality of opportunity. Her theory of representation asserts that social justice should also include changes to the social structures and norms that enable or constraint individual's ability to gain access to material and non-material goods (Young, 1990). This is because 'the norms that function to stigmatise or disadvantage are usually embedded in the assumptions under which institutions operate, and often the people who make decisions in them are not aware of the assumptions or their consequences' (Young, 2006, p. 97). Distribution is not effective if it is predicated on social structures and institutions which are in themselves, unequal in nature (Young, 1990). The representation approach to social justice therefore calls for changes to institutional practices, rules and norms that influence an individual's ability to develop and exercise the capacities afforded them through the distribution of goods.

Sen's capabilities framework of social justice is concerned with the freedom people have to pursue the lives they have reason to value $(1979 ; 1999 ; 2000)$. Its aim is to extend as well as shift attention from Rawls' primary concern with distribution of goods to how these goods enable individuals the freedom to make informed choices. A person's 'capability' refers to the level of freedom they have to achieve or choose from the various lifestyles they value (referred to as functionings). To ensure social justice, policies must enable individuals' capability set, that is, create real opportunities from which people are free to choose (Sen, 1999). Additionally, the capability approach argues for consideration of the conditions that govern people's ability to convert primary goods into their desired objectives. According to Sen (1979), the 'conversion of goods to capabilities varies from person to person substantially, and the equality of the former may still be far from the equality of the latter' (p. 219). In other words, individuals belonging to the same disadvantaged group can differ in the extent to which they convert opportunities into achievements. This is a result of the different personal, environmental and social limitations they may encounter (Sen, 1999, 1979; Wilson-Strydom, 2015). Policies aimed at achieving social justice must therefore address the individual differences among those who experience similar levels of disadvantage by enabling them to overcome barriers and convert opportunities into desired outcomes. If policies distribute goods but such goods do not enable individuals the freedom to choose or realise their desired choices, then social justice is not achieved.

The above theoretical discussion suggests that to be socially just, widening access policies should entail: distribution of goods to the benefit of the least-advantaged; representation through positive action and changes to institutional practices, and capabilities through enabling individuals from disadvantaged backgrounds the freedom to successfully enter university if they choose to, make informed choices, and address individual circumstances that can inhibit students' ability to exploit available 
opportunities. As highlighted earlier, students from low socioeconomic backgrounds remain under-represented in the competition for the limited university places available, despite the introduction of various widening access policies and practices (COWA, 2015; Hunter Blackburn et al., 2016; Sosu et al., 2016). However, to date, no studies have critically interrogated the principles underpinning the policies aimed at widening access to university in Scotland. We argue that such an analysis is both overdue and crucial in identifying synergies and tensions that can significantly influence policy effectiveness. Thus, the current study seeks to answer the research question: What synergies and tensions are inherent in policies and practices for widening access to university in Scotland?

\section{Methodology}

The data for analysis consisted of key Scottish policies on widening access to university. We define widening access policy documents as those texts that communicate principles, intentions and actions relating to increasing the number and proportion of students from economically disadvantaged backgrounds in university. To locate these documents, we conducted online searches of key websites (Universities Scotland, Scottish Funding Council, Scottish Government and Scottish Parliament) as well as using a snowball approach through citation mining. We limited our selection of policies to those published from 2011 to 2016. In total, 35 documents were analysed. These included: a prelegislative paper (Putting Learners at the Centre); Post-16 Education (Scotland) Act (2013); the preceding Post-16 Education (Scotland) Bill (2012) and their explanatory notes; policy briefs (e.g., Scottish Parliament Briefings), Scottish Funding Council's (SFC) Learning for All publications, other SFC policy briefs, Universities Scotland policy briefs; statutory policy guidelines (e.g., Outcome Agreements, Student Awards Agency Scotland (SAAS) funding guides, Scottish Government funding guides); and strategic plans of statutory organisations (e.g., SFC Strategic Plan).

The study used a theoretical framework analysis design; a qualitative method of investigating large scale applied social policy. It is a stage-based and systematic process (Ward et al., 2013) that enabled us to apply the theories of social justice outlined above to our data. First, we attended to the overall focus of the documents, the policy and practice interventions and, where applicable, the rationale underpinning the interventions to derive thematic clusters of key widening access interventions. We then took the three overarching elements of social justice from the work of Rawls, Young and Sen; that is, distribution, representation and capabilities, to develop a set of coding categories to interrogate the themes. We sought evidence of: (a) distribution of resources; (b) representation of disadvantaged groups and changes to institutional practices; (c) capabilities through enabling freedom to access university, addressing within group differences and support for disadvantaged groups to enable them to convert widening access opportunities into success.

\section{Findings and discussion}

Our analysis of the documents identified five key widening access interventions. These were: legislating for widening access; widening access outcome agreements; the provision of protected places; outreach schemes; and financial support. A summary of these widening access interventions and relevant key policy documents are presented in Table 1.

Legislating for widening access to university. A key intervention in Scotland is the development of legislation requiring the funding body and universities to widen access to higher education. Section 9(2) of the Post-16 Education (Scotland) Act (2013) gives Scottish Ministers:

the power to impose terms and conditions for the purposes of enabling, encouraging or increasing participation in fundable higher education by persons belonging to any socioeconomic group which they reasonably consider to be underrepresented in such education. (Scottish Parliament, 2013)

Section 12(1) enables the Scottish Funding Council (SFC), the statutory agency responsible for funding higher education, to impose a condition requiring universities 'to comply with widening access agreements' (Ibid). To ensure that the goals of widening access are being met, the Scottish Government made it a requirement that participation in university by traditionally underrepresented groups be reviewed and actions taken to correct imbalances (Scottish Government, 2011, p. 28).

The legislation is an effort to facilitate the Scottish Government's ambition for universal access to university education, irrespective of economic background. However, it is underpinned by the concept of meritocracy and the need for individuals to demonstrate, irrespective of their background and economic circumstances, that they merit one of the limited 'free' university places (Universities Scotland, 2012; SFC, 2015b). In this case, individuals from advantaged backgrounds are more likely to be competitive because the achievement of high examination grades is significantly influenced by socioeconomic circumstances (Chowdry et al., 2013; Crawford et al., 2016). The legislation therefore gives power to the SFC to monitor imbalances in universities and is an attempt to achieve social justice by ensuring a balance in patterns of participation that is representative of the wider society. It can be argued that the legislation provides a basis to consider notions of distribution as a means of achieving socially just access to university (Rawls, 1971). Consistent with Young's $(1990,2006)$ representational justice, the legislation also seeks to promote change to existing processes to increase the participation of economically disadvantaged groups in university education. However, the use of meritocratic criteria is a source of tension which is likely to restrict the extent to which widening access interventions benefit the most disadvantaged students, a key element for achieving distributive justice (Rawls, 1971).

Outcome agreements. Amongst other things, Outcome Agreements (OAs) between the SFC and Scottish universities require universities to specify their plans to increase the number of students from low income backgrounds. The SFC was given power by the Scottish Government to use OAs with universities to 'formalise commitment to accept more students [...] living in areas representing the most deprived 20\% or 40\%' (Scottish Parliament, 2012, p. 23). Furthermore, university funding is connected to the fulfilment of agreed widening access targets with the potential for the SFC to impose financial penalties for noncompliance:

We will ask the SFC to develop a Widening Access Outcome Agreement in partnership with lead universities and to introduce financial penalties conditional on achievement. The approach would differ from institution to institution so that, for example, local circumstances and sectoral needs would be taken into account. Such new arrangements should have, we believe, statutory force. (Scottish Government, 2011, p. 28).

The OAs are therefore positive action designed to distribute university places to economically disadvantaged groups. This policy aligns with distributive theorists (Young, 1990, 2006; 
Rawls, 1971) who argue that achieving social justice requires a redistribution of goods to benefit the least advantaged in society. It can also be interpreted as a positive intervention with several dimensions. First, policies ensuring that the demographic mix of society is reflected in university student body 'announces [the university's] acceptance of formerly excluded groups' (Young, 1990 , p. 198). Second, inclusive policies counter the 'grouprelated biases of institutions and decision-makers' (Young, 1990, p. 198). Third, a student body that reflects the wider population can increase diversity of experiences, cultures, and values which in turn, can bring about representation in decision-making processes of universities (Young, 1990).

A key feature of widening access agreements is that they are flexible and negotiable, allowing for institutional innovation. Most institutions have designed different models of 'contextual admissions', a process which takes into account an individual's 'attainment in the context of the circumstances in which it has been obtained' (SFC, 2015a, p. 5). It is based on the rationale that 'examination grades are a useful indicator of potential but they are not perfect' (Scottish Government, 2011, p. 28). Through their outcome agreements, universities specify adjustments that they wish to make for students from low income backgrounds so that they can be admitted to university with lower grades than their more advantaged peers. While this intervention appears to be consistent with Rawls' (1999) distributive arguments where social justice is achieved by giving preference to disadvantaged groups over others, there are tensions in its implementation due to the inherent flexibility of the policy. For instance, some institutions have not implemented radical policies to address the existing inequalities in their student population. Evidence from the SFC indicates that more elite (i.e., higher demand) institutions and higher demand programmes (e.g., law, medicine) are less likely to admit students from low income households (SFC, 2016a). Thus, the flexibility may lead to stratification of the type of institutions and programmes that students from disadvantaged households attend, a phenomenon observed by McCowan (2007) in his analysis of access policies in Brazil. Consequently, distributive justice is not achieved across different types of institutions. It also raises questions about the extent to which the SFC is able to use levers such as Outcome Agreements to ensure that all universities act in radically innovative ways to widen access.

Protected places. The provision of protected places for students from socioeconomically disadvantaged backgrounds has been a major strategy employed by the Scottish Government to widen access to university. In 2013, the Scottish Government committed $£ 40$ million of additional funding over four years to support 727 additional places each year for students from low socioeconomic backgrounds (SFC, 2013, p. 3). This included the provision of protected places for students to access high demand courses such as law, medicine, design and architecture in high demand institutions (SFC, 2011, 2016b). About 2,100 additional access places were provided over three years to overcome the effects of competition for entry to elite institutions. The SFC stated that the funding was 'targeted at the most selective institutions with the highest student demand, and which have not in the past recruited significant numbers of students from the most deprived areas' (SFC, 2016b, p. 9).

Additionally, protected places were provided for students to enter university through an 'articulation route', which in the Scottish context, refers to the movement of students from a college course (i.e., post-secondary diploma level) into second or third year of a university degree. The SFC noted that 'to support this initiative, from 2013/2014 we are making available over 1000

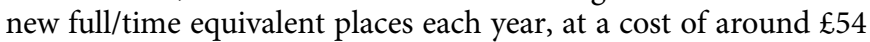

million over four years' (SFC, 2013, p. 4). Because a significant proportion of college students are from socioeconomically disadvantaged backgrounds (e.g., SFC, 2014a), articulation is perceived as 'an access route that enables a wider range of students to access university than through the 'traditional' route from school' (SFC, 2016a, p. 2).

In accordance with distributive (Rawls, 1971) and representational (Young, 2006) notions of social justice, the provision of protected places represents positive action to increase the number of under-represented groups gaining entry to university. By providing additional spaces that can only be taken up by disadvantaged individuals, institutions therefore reduce competition for places that disadvantaged individuals would have otherwise been unlikely to win. Consistent with Young's argument $(1990 ; 2006)$, protecting places at university, particularly on high demand courses and in elite institutions, acknowledges that places in these courses and in these institutions, have traditionally been the preserve of the most privileged members of society. This is particularly important because those who occupy positions of power in society have generally attended elite institutions (MacMillan et al., 2015; Social Mobility and Child Poverty Commission, 2015). Ensuring equal access to elite institutions may contribute to a greater range of people occupying positions of influence in society, although this is by no means guaranteed (e.g., Crawford et al., 2016).

The provision of protected places was a one-off intervention and it is not clear that this will be continued when the current provision comes to an end. Still, it is important that the efficacy of protected places is carefully monitored to ensure that those who benefit from the distribution of additional university places are indeed students from the most disadvantaged backgrounds, a central tenet of Rawls' theory of distribution (Rawls, 1999). The limited evidence available suggests that only about $23 \%$ of articulating students from college to university are from the lowest deprivation quintile, despite being overrepresented in the college student body as a proportion of the general Scottish population (SFC, 2015a, 2016a). Finally, the provision of protected places should be accompanied by cultural change in university admissions policies to ensure that widening access initiatives are fully embedded within systems.

Outreach schemes. National outreach schemes in Scotland have been established to provide information, advice and guidance to students attending schools with low progression rates to university, most of which are in disadvantaged areas (SFC, 2015a). These outreach programmes offer university application support, interview preparation, advice on budgeting and living away from home, and information about what to expect of university life (Universities Scotland, 2013; SFC, 2015c). The main national outreach scheme, the Schools for Higher Education Programme for secondary school students, (SHEP) was established to support 'universities to develop a programme of guidance and support for pupils from schools in the lowest quintile for progression to higher education' (Scottish Government, 2011, p. 26). Other national outreach programmes work with selected schools to increase the number of students from low income households enroling in high demand disciplines such as law and medicine, as well as creative disciplines such as the arts and music (SFC, 2016b, p. 2).

The provision of outreach extends the distribution of goods to include what Young $(1990,2006)$ terms non-material goods. This ensures that individuals develop the skills and attributes to successfully apply for, and gain entry to university, including those that offer protected places. The activities undertaken develop the forms of social and cultural capital that 
disadvantaged individuals may not necessarily possess. For example, admission processes that include an interview or require students to provide a personal statement, favour those students who have the necessary cultural and social capital to compete for places. Students from low income backgrounds may not have family members who have been to university or who can offer guidance and advice about how to effectively showcase their skills (Avery, 2010; Sosu et al., 2016). It can be claimed that outreach schemes to some extent fulfil a central tenet in a capabilitiesbased approach to social justice because they enable students to make informed choices, take advantage of widening access opportunities, as well as prepare them to succeed at university (Sen, 1999; Wilson-Strydom, 2015).

There are however, some tensions in the provision of outreach due to limited resources and funding. First, funding is only available to provide outreach for schools where fewer than $22 \%$ of students progress to higher education. This assumes that students from low income households who attend higher progression schools receive greater support and guidance than their peers who attend low progression schools. Thus, the distribution of outreach schemes attempts to take account of assumed within-group differences which Sen $(1979,1999,2000)$ argues is important for achieving social justice. However, if the type of school attended makes no difference to the amount of guidance received, then low income students who attend high progression schools may be disadvantaged through this approach to allocating outreach. Another tension arising from limited resources for outreach provision is that spaces are limited, even in schools where there is outreach. To qualify, students must demonstrate they have the potential for higher education in terms of their academic performance and personal commitment as defined by their teachers (SFC, 2014b). Therefore, students in low progression schools who are selected for these programmes are, by virtue of being selected for participation, the most advantaged in the school. There is also evidence to suggest that low income students who may not actively consider higher education and who attend schools where outreach is available to all students, are the ones most likely to benefit from guidance and support (Domina, 2009).

Financial support. Financial support constitutes another key policy adopted by the Scottish Government to increase the number of students from disadvantaged backgrounds enroling in university. The Government argues that universal free tuition for all Scottish domiciled students will remove the financial burden from them. In a 2011 document setting out legislative intentions on higher education, the governing party stated that:

We have ensured that financial concerns do not create unnecessary barriers to accessing higher education. We abolished the Graduate Endowment Fee and have pledged that no tuition fees, upfront or backdoor, will be introduced under an SNP [Scottish National Party] administration (Scottish Government, 2011, p. 26).

The provision of free university tuition is one of the main policies that distinguish Scotland from the three other jurisdictions that make up the UK (England, Wales and Northern Ireland) where students pay for tuition through loans. Theoretically, free tuition enables all students to graduate with a lower debt burden, with students only bearing the cost of living expenses. However, free tuition is limited to students who study in a Scottish university. Thus, the universalist approach to free higher education does not apply to those Scottish students who, for a range of reasons, study outside Scotland. A student from a disadvantaged background who enrols at a university in another part of the UK must fund their tuition through a loan. The limitation placed on free tuition is therefore inconsistent with Rawls argument (1999) that to achieve social justice, distribution of resources must be of benefit to the most disadvantaged.

Apart from universal free tuition for all Scottish domiciled students, loans and means-tested financial support covering living costs may enable students from disadvantaged groups to take-up university places (Scottish Government, 2014b). All students are entitled to a loan of $£ 4750$ per year to meet living costs while studying, irrespective of parental income. However, students from low income backgrounds can obtain a loan of up to $£ 6750$ depending on qualifying criteria (Students Awards Agency Scotland [SAAS], 2016). This means that students from low income households can more easily cover living costs during their studies, thereby enabling them to progress through university without significant financial hardships. However, this also means that students from low income households are likely to graduate with a higher level of debt in comparison to more affluent peers, thus potentially putting them at further disadvantage.

Finally, low income students also receive financial support in the form of grants. A standard grant of $£ 500$ to $£ 1875$ per year is awarded to students depending on parental income and circumstances (SAAS, 2016). Additionally, it is recognised that some low income students may experience further disadvantages such as disability. The government agency responsible for grants notes that 'depending on your personal circumstances, you may be able to apply for other living-costs grants that you do not have to pay back' (SAAS, 2016, p. 7). It also identifies a range of grants available to those with additional disadvantage such as having a dependant, being a lone parent, having a disability, and living under the care of the state as a child (SAAS, 2016).

Distributive and representational theorists (Rawls, 1999; Young, 2006) would describe the distribution of grants as an affirmative action aiming to increase enrolment of students from low income backgrounds. It also addresses to some degree Sen's (1999) argument that individuals experiencing similar forms of disadvantage differ in their ability to convert material goods to capabilities. Grants attending to group differences enable low income students with additional disadvantages to convert widening access opportunities into actual enrolment at university. However, the available grants appear to be generally small and limited in comparison to support through loans. This raises questions about the extent to which these can serve as a catalyst for achieving social justice.

\section{Concluding comments}

This study identified the synergies and tensions inherent in policies aimed at increasing access to university for students from economically disadvantaged backgrounds. A theoretical framework drawing on Rawls, Young and Sen's conceptions of social justice provided us with a theoretical lens to systematically interrogate the body of policy documents under scrutiny. Our analysis indicates that attempts to widen access in Scotland are supported by legislative instruments, statutory requirements for universities to set access related targets, increased spending on protected places, outreach schemes, free tuition, loans and meantested grants.

We identified synergies between these widening access policies that targets the multiple causes of the access gap. For instance, legislative instruments were backed by government actions such as increased financial investment for protected places, the requirement for universities to consider changing their admissions practices, support for outreach activities, and the provision of universal free tuition. Synergies were also evident in the multiple conceptions of social justice that underpinned the widening access policies being deployed. Distributional conceptions of 
justice (Rawls, 1999; Young, 2006) were evident through the allocation of material and non-material goods in the form of protected places, outreach and the limited number of grants to students from low income households. Representational conceptions of social justice (Young, 2006, 1990) are beginning to be evident in changes to existing norms and structures. Although there is still much to be done to achieve the goals of representation, legislation and outcome agreements represent a positive start. Finally, a capabilities conception of social justice (Sen, 1999) was reflected through outreach schemes and limited means-tested financial support that enable some students to make informed choices, and take advantage of the access opportunities available to them. We argue that these synergies should be strengthened to close the gap in access to higher education. However, despite this being a policy priority, the available evidence so far suggests only a limited increase in the number of students from economically disadvantaged backgrounds gaining access to university over the past decade (COWA, 2015; Hunter Blackburn et al., 2016; Sosu et al., 2016).

We also found tensions inherent in current policies and practices which may explain the limited impact of these policies. Ambitions of widening access are tempered by competition for limited university places, and the use of meritocratic admissions processes which do not favour the most disadvantaged. Flexible Outcome Agreements potentially mean that institutions do not need to adopt radical approaches to closing the access gap. Additionally, resource constraint for outreach as well as criteria for identifying who qualifies for support means that outreach programmes are not available to all disadvantaged students. There is also a high likelihood that such programmes may benefit the least disadvantaged students attending low progression schools. Furthermore, the design of financial support systems means that students from low income households may incur a higher debt than their more affluent peers.

We argue there is a need for a system that enables access to university for anyone who meets the entry requirements. This may require an expansion of the number of university places currently available. The ultimate success of such strategy would be judged against how well it delivers on the benefits of university education such as better labour market outcomes and earnings. Additionally, there should be an ongoing requirement for universities to demonstrate the impact of their access policies on increased and more representative enrolments. Such evidence is important for sustaining and guiding future widening access policy and practice (Reed et al., 2015). An approach which provides high quality guidance and support to all students from low income families, irrespective of the type of school attended, is required in order to enable students to make informed choices. Ultimately, policy makers should address the unintended consequences of offering financial support primarily via loans to students from low income households. This could be done by increasing grants to offset the burden of debt for those from low income households.

The present study is limited in several ways. First, we only examined policies from 2011 to 2016 . While these policies reflect a critical period in the development of widening access legislation in Scotland, they are necessarily a snapshot. Second, our analysis does not consider broader policies aimed at reducing overall poverty in society or in relation to improving attainment in schools. Third, many of the policies we analysed focus on support at a late stage in students' educational careers. Currently there is a focus in Scottish policy on early stage interventions to mitigate the impact of poverty on educational outcomes. Future research into the effect of these early interventions on educational outcomes, and subsequently, access to university, will help shed further light on the interventions that close the access gap.
Fourth, the present study does not seek to empirically evaluate policy effectiveness. While our study identified synergies and tensions within widening access policies, analyses of empirical data are required to identify the extent to which policies increase access to university for those from disadvantaged backgrounds. Finally, although access to university is a starting point, ensuring equity across educational experiences is equally necessary. Future studies should examine how existing policies address equity of experience and outcomes in higher education.

Through the use of a multifaceted theoretical framework of social justice to review widening access policies on a national level, this study makes a unique contribution to the field. Our analysis has revealed synergies that need to be strengthened, as well as tensions that should be addressed. Attending to these synergies and tensions will contribute to increased equity and access to university.

Received: 1 August 2018 Accepted: 26 November 2018 Published online: 18 December 2018

\section{References}

Avery C (2010) The effects of college counseling on high-achieving, low-income students. National Bureau of Economic Research Working Paper, No. 1635.9. http://www.nber.org/papers/w16359. Accessed 1 Nov 2018

Chowdry H, Crawford C, Dearden L, Goodman A, Vignoles A (2013) Widening participation in higher education: analysis using linked administrative data. J R Stat Soc Ser A 176:431-457

Commission on Widening Access (2015) Commission on widening access interim report. https://www2.gov.scot/Publications/2015/11/9302. Accessed 1 Nov 2018

Crawford C, Gregg P, Macmillan L, Vignoles A, Wyness G (2016) Higher education, career opportunities, and intergenerational inequality. Oxf Rev Econ Policy 32(4):553-575

Domina T (2009) What works in college outreach: assessing targeted and schoolwide interventions for disadvantaged Students. Educ Eval Policy Anal 31(2):127-152

Hunter Blackburn L, Kadar-Satat G, Riddell S, Weedon E (2016) Access in Scotland: access to higher education for people from less advantaged backgrounds in Scotland. Sutton Trust, London

Iannelli C, Smyth E, Klein M (2015) Curriculum differentiation and social inequality in higher education entry in Scotland and Ireland. Br Educ Res J 42 (4):561-581

Ilie S, Rose P (2016) Is equal access to higher education in South Asia and subSaharan Africa achievable by 2030? High Educ 72(4):435-455

Jerrim J, Chmielewski AK, Parker P (2015) Socioeconomic inequality in access to high-status Colleges: a cross-country comparison. Res Social Stratif Mobil 42:20-32

Liu A (2011) Unravelling the myth of meritocracy within the context of US Higher Education. High Educ 62:383-397

MacMillan L, Tyler C, Vignoles A (2015) Who gets the top jobs? The role of family background and networks in recent graduates'access to high-status professions. J Social Policy 44:487-515

McCowan T (2007) Expansion without equity: an analysis of current policy on access to higher education in Brazil. High Educ 53:579-598

Msigwa FM (2016) Widening participation in higher education: a social justice analysis of student loans in Tanzania. High Educ 72:541-556

Organisation for Economic Co-operation and Development (OECD) (2015) Education Indicators in Focus: How do differences in social and cultural background influence access to higher education and the completion of Studies? https://www.oecd-ilibrary.org/docserver/5jrs703c47s1-en.pdf? expires $=1544714023 \& i d=i d \&$ accname $=$ guest\&checksum $=5$ C21A813F8E8DE452D2D770157723D95, Accessed 1 Nov 2018

Pitman T, Koshy P, Phillimore J (2015) Does accelerating access to higher education lower its quality? The Australian experience. High Educ Res Dev 34:609-623

Rawls J (2001) Justice as fairness: a restatement. Harvard University Press, Cambridge MA

Rawls J (1999) A theory of justice (Revised edition). Harvard University Press, Cambridge MA

Rawls J (1971) A theory of justice. Harvard University Press, Cambridge, MA

Reed A, King A, Whiteford G (2015) Re-conceptualising sustainable widening participation: evaluation collaboration and evolution. High Educ Res Dev $34: 383-396$ 
Scottish Funding Council (SFC) (2016a) Articulation and progression. Access and Inclusion Committee Annex G, 24 May. http://www.sfc.ac.uk/web/FILES/ CMP_AccessandInclusionCommittee24May2016_24052016/ AIC16_13_Annex_G_Chapter_5_Articulation_and_progression.pdf. Accessed 1 Nov 2018

Scottish Funding Council (SFC) (2016b) Overview of SFC strategic investments in access. Access and Inclusion Committee Annex J, 24 May. http://www.sfc.ac. uk/web/FILES/CMP_AccessandInclusionCommittee24May2016_24052016/ AIC16_13_Annex_J_Overview_of_SFC_strategic_investments_in_access.pdf Accessed 1 Nov 2018

Scottish Funding Council (SFC) (2015a) Learning for all: measures of success. Ninth update-March 2015. Access and Inclusion Committee Agenda Item 11, 16 Feb. http://www.sfc.ac.uk/web/FILES/Statistical_publications_ SFCST062015_LearningforAllMeasuresofSuccess/SFCST062015_Learning for_All_2015_Measures_of_Success.pdf Accessed 1 Nov 2018

Scottish Funding Council (SFC) (2015b) Scottish Funding Council Strategic Plan 2015-2018. http://www.sfc.ac.uk/web/FILES/Corporate_publications_ SFCCP022015_ScottishFundingCouncilStrategicPlan2015/SFCCP022015 SFC_Strategic_Plan_2015-18.pdf. Accessed 1 Nov 2018

Scottish Funding Council (SFC) (2015c) Annual reports and review recommendation implementation update. Access and Inclusion Committee Agenda Item 10, 3 Sept: Schools for Higher Education Programme (SHEP)-2013/ 2014. http://www.sfc.ac.uk/web/FILES/CMP_AccessandInclusionCommittee 3September2015_03092015/AIC15_29_SHEP_annual_reports.pdf. Accessed $1 \mathrm{Nov}$

Scottish Funding Council (SFC) (2014a) Learning for all: Eighth update-statistics for 2012-2013. http://www.sfc.ac.uk/web/FILES/Statistical_publications_ SFCST062014_LearningforAlleighthupdatereportonmea/Learning_for_All_ 2014_report.pdf. Accessed 1 Nov 2018

Scottish Funding Council (SFC (2014) Access and inclusion committee agenda Item 5, 4 Sept. Schools for Higher Education Programme (SHEP) reviewinterim report. SFC, Edinburgh

Scottish Funding Council (SFC) (2013) 2013/2014 university sector outcome agreements. http://www.sfc.ac.uk/web/FILES/Funding_Outcome_ Agreements_2013-14/University_Sector_Outcome_Agreements_2013-14_Summary.pdf. Accessed 1 Nov 2018

Scottish Funding Council (SFC) (2011) Learning for all: fifth update report on measures of success. http://www.webarchive.org.uk/wayback/archive/ 20111011231402/http://www.sfc.ac.uk/web/FILES/Our_Priorities_Access/ Learning_for_All_2011.pdf. Accessed 1 Nov 2018

Scottish Government (SG) (2016) A blueprint for fairness: the final report of the Commission on Widening Access. March 2016. http://www.gov.scot/ Resource/0049/00496535.pdf. Accessed 1 Nov 2018

Scottish Government (2014a) First Minister-Programme for Government. https:// news.gov.scot/speeches-and-briefings/first-minister-programme-forgovernment. Accessed 1 Nov 2018

Scottish Government (2014b) Helping you meet the costs of learning and training: your guide to funding 2014/2015. http://www.gov.scot/Resource/0045/ 00453563.pdf. Accessed 1 Nov 2018

Scottish Government (2011) Putting learners at the centre: delivering our ambitions for post-16 education. http://www.gov.scot/resource/doc/357943/ 0120971.pdf. Accessed 1 Nov 2018

Scottish Parliament (2013) Post-16 Education (Scotland) Act 2013. http://www. legislation.gov.uk/asp/2013/12/contents. Accessed 1 Nov 2018

Scottish Parliament (2012) Post-16 Education (Scotland) Bill explanatory notes (and other accompanying documents). http://www.parliament.scot/S4_Bills/ Post-16\%20Education\%20Bill/b18s4-introd-en.pdf. Accessed 1 Nov 2018

Sen A (1979) Equality of what? The Tanner lecture on human values. Stanford University, California

Sen A (2000) The idea of justice. Penguin, London

Sen A (1999) Development as freedom. Oxford University Press, Oxford
Social Mobility and Child Poverty Commission (2015) Elitist Scotland? http:// www.davidhumeinstitute.com/wp-content/uploads/2015/12/ELITISTSCOTLAND_FINAL-REPORT.pdf. Accessed 1 Nov 2018

Sosu E and Ellis S (2014) Closing the attainment gap in Scottish Education. http:// www.jrf.org.uk/sites/files/jrf/education-attainment-scotland-full.pdf. Accessed 1 Nov 2018

Sosu E M, Smith L N, McKendry S, Santoro N and Ellis S (2016) Widening access to higher education for students from economically disadvantaged backgrounds: What works and why? https://pureportal.strath.ac.uk/files-asset/ 55895221/

Sosu_etal_2016_widening_access_to_higher_education_for_students_from_economically_disadvantaged_backgrounds.pdf Accessed 1 Nov 2018

Student Awards Agency Scotland (2016) Funding Guide: 2016-2017. https://www. saas.gov.uk/ forms/funding guide.pdf. Accessed 1 Nov 2018

Universities Scotland (2013) Access all areas. http://www.universities-scotland.ac. uk/uploads/ACCESS\%20ALL\%20AREAS\%20final.pdf. Accessed 1 Nov 2018

Universities Scotland (2012) Widening access to university. http://www. universities-scotland.ac.uk/uploads/WideningAccess\%20July12.pdf. Accessed 1 Nov 2018

United Nations Educational, Scientific and Cultural Organization (UNESCO) (2015) Incheon declaration: Education 2030: towards inclusive and equitable quality education and lifelong learning for all. World EducationForum 2015, Incheon, Republic of Korea

Ward D, Furber C, Tierney S, Swallow V (2013) Using framework analysis in nursing research: a worked example. J Adv Nurs 69(11):2423-2431

Wilson-Strydom M (2015) University access and theories of social justice: contributions of the capabilities approach. High Educ 69(1):143-155

Young IM (2006) Education in the context of structural injustice: a symposium response'. Educ Philos Theory 38(1):93-103

Young IM (1990) Justice and the politics of difference. Princeton University Press, Princeton, NJ

\section{Acknowledgements}

This study was funded through the Scottish Funding Council Impact for Access Fund

\section{Additional information}

Competing interests: The authors declare no competing interests.

Reprints and permission information is available online at http://www.nature.com/ reprints

Publisher's note: Springer Nature remains neutral with regard to jurisdictional claims in published maps and institutional affiliations.

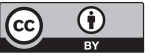

Open Access This article is licensed under a Creative Commons Attribution 4.0 International License, which permits use, sharing, adaptation, distribution and reproduction in any medium or format, as long as you give appropriate credit to the original author(s) and the source, provide a link to the Creative Commons license, and indicate if changes were made. The images or other third party material in this article are included in the article's Creative Commons license, unles indicated otherwise in a credit line to the material. If material is not included in the article's Creative Commons license and your intended use is not permitted by statutory regulation or exceeds the permitted use, you will need to obtain permission directly from the copyright holder. To view a copy of this license, visit http://creativecommons.org/ licenses/by/4.0/.

(ㄷ) Crown 2018 